\title{
P0184
}

\section{EFFECT OF BACKGROUND LUMINANCE CALCULATION METHOD ON VL VALUE}

\author{
Burcu Buyukkinaci et al.
}

DOI 10.25039/x46.2019.PO184

from

CIE x046:2019

\section{Proceedings}

of the

29th CIE SESSION

Washington D.C., USA, June 14 - 22, 2019

(DOI 10.25039/x46.2019)

The paper has been presented at the 29th CIE Session, Washington D.C., USA, June 14-22, 2019. It has not been peer-reviewed by CIE.

(C) CIE 2019

All rights reserved. Unless otherwise specified, no part of this publication may be reproduced or utilized in any form or by any means, electronic or mechanical, including photocopying and microfilm, without permission in writing from CIE Central Bureau at the address below. Any mention of organizations or products does not imply endorsement by the CIE.

This paper is made available open access for individual use. However, in all other cases all rights are reserved unless explicit permission is sought from and given by the CIE.

CIE Central Bureau

Babenbergerstrasse 9

A-1010 Vienna

Austria

Tel.: +4317143187

e-mail: ciecb@cie.co.at

www.cie.co.at 


\title{
EFFECT OF BACKGROUND LUMINANCE CALCULATION METHOD ON VL VALUE
}

\author{
Buyukkinaci, B. ${ }^{1}$, Onaygil, S. ${ }^{2}$, Yurtseven, M.B. ${ }^{2}$, Guler, O. ${ }^{2}$ \\ ${ }^{1}$ ISBAK Istanbul IT and Smart City Technologies Inc., Istanbul, TURKEY, \\ 2 Istanbul Technical University, Energy Institute, Istanbul, TURKEY \\ bbuyukkinaci@isbak.istanbul
}

DOI 10.25039/x46.2019.PO184

\begin{abstract}
When calculating the visibility of a target object in road lighting calculations, there is no clearly accepted approach to what should be considered as a background luminance. Different methods may be used such as taking the average background luminance of the bottom and top, right and left, the four sides of the target or the background luminance on that side of the target that leads to the highest contrast. The objective of this study is to show how given background luminances change the VL values for targets. Thus, it is to draw attention and contribute to the need to define the method of background luminance determination which will be accepted as general in VL calculations for the road lighting designs.
\end{abstract}

Keywords: e.g. Road lighting, visibility level, background luminance

\section{Introduction}

Adrian's VL (Visibility Level) calculation model is mostly used for road lighting. This model is based on the idea that, in levels of mesopic vision, such as in road lighting, visibility is mainly sustained by brightness difference perception which means that we need a certain luminance difference between target and background to perceive it [Adrian, 1989].

In Adrian's model visibility level is defined as:

$$
V L=\frac{\Delta L_{\text {actual }}}{\Delta L_{\text {threshold }}}
$$

with;

$$
\Delta L=L_{T}-L_{b}
$$

where;

$L_{T} \quad$ is the target luminance;

$L_{b} \quad$ is the background luminance.

In road lighting applications the road surface luminance is not uniform. Because the driver's eyes continuously scan the road surface while driving, it is not clear what to take as the background luminance for a specific target object. It is possible to take the average background luminance of the bottom and top or of the four sides of the target. However, from a visibility point of view, such an averaging procedure is not realistic: it is quite possible that on all sides of the target the background luminance is quite different from the target luminance itself, while the average value is the same as the target luminance. An example for this situation is shown in Figure 1 [van Bommel, 2015]. On the right of Figure 1 the average of luminances at the sides of the target is equal to the target luminance itself. This may incorrectly suggest that the target is invisible even though the target is on the right is sufficiently visible. 

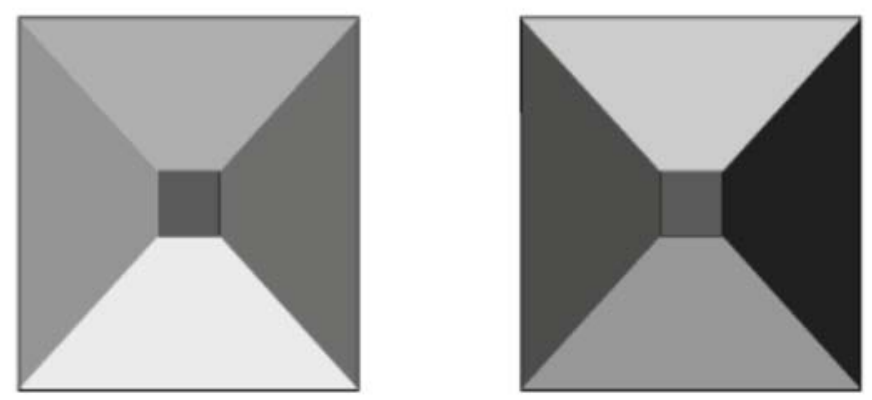

Figure 1 - Schematic illustration of different background luminances around a target on a road surface with non-uniform luminance

In practical illuminating engineering emphasis is usually on the contrast at the border between two adjacent areas in the field of view. This is especially relevant for the detection of objects on the road under public or vehicle lighting. This is called border contrast [Schreuder, 2008].

Brémond in his study compared six visibility level assessment methods. The background luminance was set as the luminance at the bottom of the target, as the mean luminance around the target, or as the luminance associated with the maximum target contrast. The adaptation luminance was set either to the background luminance or to the mean luminance. The best nonlinear fit between computed visibility level and target detection performance was found using the maximum contrast over the four sides of the square target, and setting the adaptation luminance to a unique estimated road luminance instead of the local background luminance [Brémond R, 2011].

The background luminance is taken as the average of the point luminance at the bottom of the target and at the top of the target for STV (small target visibility) measurements in IES standards [IESNA, 2014].

The objective of this study is to show how given background luminances change the VL values for targets. Thus, it is to draw attention and contribute to the need to determine the method of background luminance determination which will be accepted as general in VL calculations for the road lighting designs.

\section{Luminance Measurements on Test Road}

The luminance measurements for the visibility level (VL) calculations for this study are carried out on a 250 meters long test road in Istanbul Technical University (ITU) Ayazaga Campus. There are two lanes on the test road. Each lane is 3.5 meters wide and the total width of the road is 7 meters. The lighting arrangement is single sided from the left. Eight lighting poles are installed with 30 meters spacing. 4000K LED luminaires are fixed at 10 meters on the lighting poles. The luminous flux of the luminaires is controlled by $1-10 \mathrm{~V}$ control system and can be dimmed to the desired level. Thus, different quality criteria can be ensured for different lighting classes on the test road.

The luminances are measured for the fixed observer, located 60 meters behind the calculation area, which is used in the calculation of the road surface luminance in current standards and recommendations. The luminous flux of the luminaires is adjusted to satisfy M2 road lighting class according to the EN 13201-1 [CEN 2015] standard. A $20 \mathrm{~cm} \times 20 \mathrm{~cm}$ flat square target with a Lambertian surface is used, which is shown in Figure 2. Reflectance of the target was selected as 0.20 . 


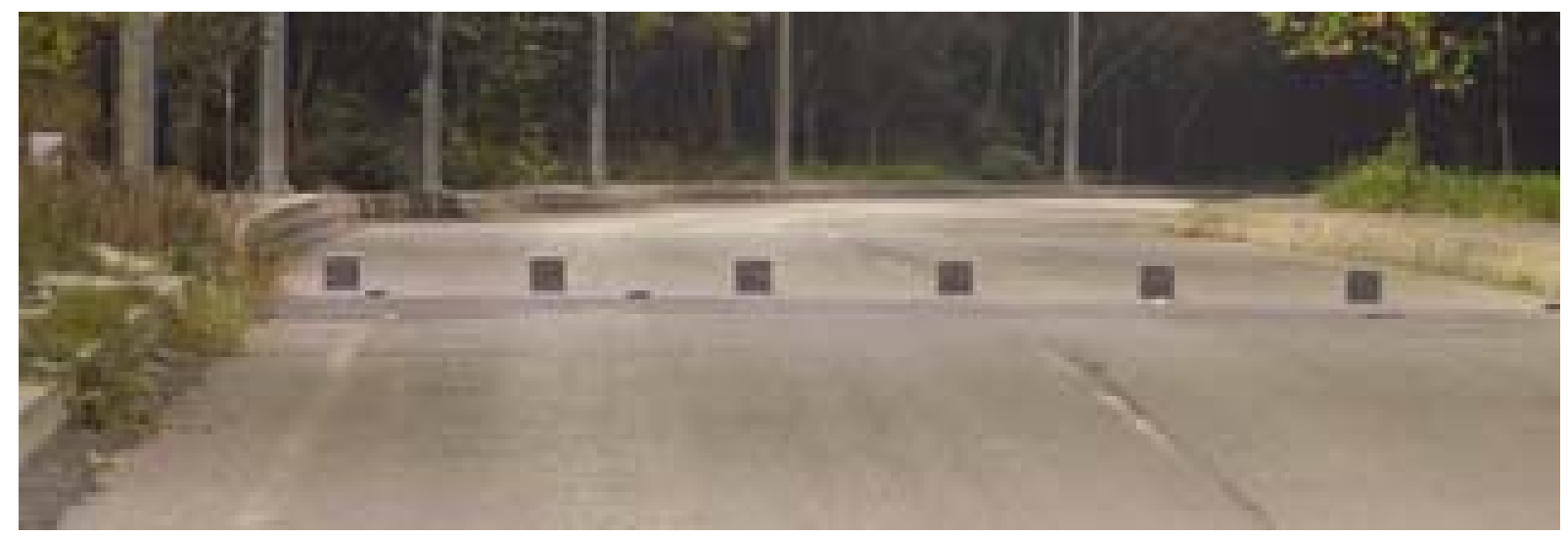

Figure 2 - Targets on the test road

\section{Visibility Level Calculations}

VLs of target for all measurement points on the test road are calculated for the average background luminance at the right and left sides of the target, the average background luminance at the bottom and at the top of the target, the average background luminance at four sides of the target and the background luminance with the maximum contrast.

The VL values for all measurement points and the average of these values are given in Tables 1 and 4.

Table 1 - VLs for the background luminance is taken as the average at the right and at the left side of the target.

\begin{tabular}{|c|c|c|c|c|c|c|c|}
\hline \multirow{12}{*}{ 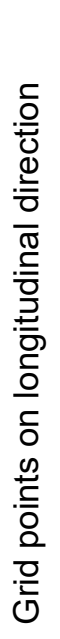 } & \multicolumn{7}{|c|}{ Grid points on transverse direction } \\
\hline & & 1 & 2 & 3 & 4 & 5 & 6 \\
\hline & 10 & 4.61 & 7.56 & 9.83 & 9.60 & 7.25 & 7.04 \\
\hline & 9 & 4.86 & 8.78 & 10.13 & 9.37 & 6.96 & 6.57 \\
\hline & 8 & 4.91 & 9.18 & 10.50 & 9.38 & 6.48 & 6.05 \\
\hline & 7 & 6.06 & 9.52 & 10.41 & 8.74 & 6.50 & 5.88 \\
\hline & 6 & 6.04 & 9.69 & 10.48 & 8.17 & 5.54 & 5.34 \\
\hline & 5 & 5.48 & 9.31 & 9.88 & 7.63 & 5.37 & 5.96 \\
\hline & 4 & 4.62 & 7.43 & 7.92 & 6.34 & 2.86 & 4.91 \\
\hline & 3 & 4.10 & 7.42 & 6.60 & 6.13 & 4.53 & 4.90 \\
\hline & 2 & 6.80 & 8.49 & 8.31 & 7.67 & 5.65 & 6.92 \\
\hline & 1 & 11.03 & 12.54 & 12.71 & 12.02 & 10.94 & 11.61 \\
\hline & & & & & & Average & 7.63 \\
\hline
\end{tabular}


Table 2 - VLs for the background luminance is taken as the average at the bottom and at the top of the target.

\begin{tabular}{|c|c|c|c|c|c|c|c|}
\hline \multirow{12}{*}{ 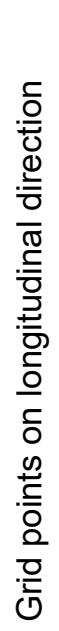 } & \multicolumn{7}{|c|}{ Grid points on transverse direction } \\
\hline & & 1 & 2 & 3 & 4 & 5 & 6 \\
\hline & 10 & 5.13 & 6.35 & 7.14 & 9.14 & 8.05 & 7.27 \\
\hline & 9 & 4.69 & 6.43 & 7.36 & 9.09 & 7.74 & 7.03 \\
\hline & 8 & 4.19 & 6.64 & 7.71 & 9.01 & 7.35 & 6.27 \\
\hline & 7 & 3.30 & 5.70 & 8.07 & 9.36 & 6.96 & 5.54 \\
\hline & 6 & 2.66 & 6.60 & 9.52 & 8.34 & 5.60 & 4.62 \\
\hline & 5 & 1.79 & 6.58 & 9.95 & 7.86 & 5.84 & 6.34 \\
\hline & 4 & 4.35 & 8.32 & 10.14 & 7.15 & 3.13 & 6.50 \\
\hline & 3 & 5.15 & 9.70 & 9.59 & 7.90 & 5.97 & 7.12 \\
\hline & 2 & 8.08 & 11.16 & 10.22 & 9.16 & 7.57 & 8.18 \\
\hline & 1 & 10.58 & 12.18 & 12.02 & 11.69 & 9.70 & 10.34 \\
\hline & & & & & & Average & 7.45 \\
\hline
\end{tabular}

Table 3 - VLs for the background luminance is taken as the average of all four sides of the target.

\begin{tabular}{|c|c|c|c|c|c|c|c|}
\hline \multirow{12}{*}{ 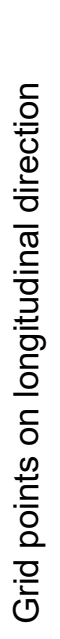 } & \multicolumn{7}{|c|}{ Grid points on transverse direction } \\
\hline & & 1 & 2 & 3 & 4 & 5 & 6 \\
\hline & 10 & 4.88 & 6.99 & 8.64 & 9.37 & 7.66 & 7.16 \\
\hline & 9 & 4.77 & 7.72 & 8.91 & 9.23 & 7.36 & 6.80 \\
\hline & 8 & 4.56 & 8.04 & 9.26 & 9.20 & 6.93 & 6.16 \\
\hline & 7 & 4.82 & 7.88 & 9.34 & 9.06 & 6.73 & 5.71 \\
\hline & 6 & 4.55 & 8.32 & 10.02 & 8.26 & 5.57 & 4.99 \\
\hline & 5 & 3.84 & 8.07 & 9.91 & 7.75 & 5.61 & 6.15 \\
\hline & 4 & 4.49 & 7.89 & 9.11 & 6.75 & 3.00 & 5.74 \\
\hline & 3 & 4.64 & 8.64 & 8.22 & 7.06 & 5.28 & 6.08 \\
\hline & 2 & 7.46 & 9.93 & 9.32 & 8.44 & 6.66 & 7.57 \\
\hline & 1 & 10.81 & 12.37 & 12.37 & 11.86 & 10.35 & 11.00 \\
\hline & & & & & & Average & 7.59 \\
\hline
\end{tabular}


Table 4 - VLs for the background luminance is taken as the luminance on that side of the target that leads to the highest contrast.

\begin{tabular}{|c|c|c|c|c|c|c|c|}
\hline \multirow{12}{*}{ 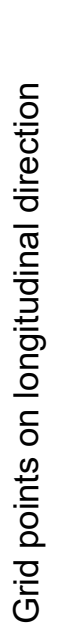 } & \multicolumn{7}{|c|}{ Grid points on transverse direction } \\
\hline & & 1 & 2 & 3 & 4 & 5 & 6 \\
\hline & 10 & 7.47 & 9.03 & 10.16 & 9.85 & 9.12 & 7.90 \\
\hline & 9 & 6.86 & 9.43 & 10.22 & 10.53 & 9.07 & 7.71 \\
\hline & 8 & 6.13 & 10.08 & 10.73 & 10.93 & 8.70 & 7.20 \\
\hline & 7 & 6.19 & 10.27 & 10.47 & 11.61 & 8.36 & 6.30 \\
\hline & 6 & 6.07 & 10.68 & 11.03 & 10.60 & 6.77 & 5.51 \\
\hline & 5 & 6.02 & 10.35 & 11.72 & 9.26 & 6.35 & 7.60 \\
\hline & 4 & 5.24 & 8.99 & 12.00 & 8.65 & 3.36 & 8.37 \\
\hline & 3 & 7.21 & 10.84 & 11.43 & 8.69 & 6.43 & 8.02 \\
\hline & 2 & 8.96 & 12.09 & 11.02 & 9.28 & 8.44 & 8.53 \\
\hline & 1 & 11.33 & 13.17 & 12.86 & 12.20 & 11.14 & 11.61 \\
\hline & & & & & & Average & 9.10 \\
\hline
\end{tabular}

\section{Results and Conclusion}

As a result of the VL calculations, when the background luminance is taken as the average of the point luminances at the right and left sides of the target, the average of the point luminances at the bottom and at the top of the target, and the average of the point luminances at all four sides of the target the average VL values are calculated as $7.63,7.45$ and 7.59 respectively. These values are very close. However when the background luminance is taken as the luminance on that side of the target that leads to the highest contrast the calculated average $V L$ is 9.10 . This is approximately $20 \%$ higher than the former three cases.

From the results of this study it is shown that the method of background luminance calculation is very important when calculating the visibility of a target. However, there is no clearly accepted approach to what should be considered as a background luminance. There is a suggestion that when the background luminance is taken as an average value, it may lead to an incorrect evaluation of the target's visibility. For this reason, in the assessment of visibility in road lighting, the calculation method for background luminance should be specifically defined and included in the standards and recommendations.

\section{References}

ADRIAN, W. 1989. Visibility of Targets: Model for Calculation. Lighting Res. Technol., 21, 181188.

VAN BOMMEL, W. 2015. Road Lighting: Fundamentals, Technology and Application. Switzerland: Springer.

SCHREUDER, D. 2008. Outdoor Lighting: Physics, Vision and Perception. Berlin: Springer.

BREMOND, R. DUMONT, E. LEDOUX, V. MAYEUR, A. 2011. Photometric Measurements for Visibility Level Computations. Lighting Res. Technol., 43, 119-128.

IESNA 2014. ANSI/IES RP-8-14, Roadway Lighting, New York, IESNA.

CEN 2015. CEN-EN 13201-1:2015. Road Lighting Part 1: Selection of Lighting Classes. Brussels: CEN. 